\title{
Playful activity remained constant while electronics use increased in children during social distancing amidst the COVID-19 outbreak: A Poá's pilot study
}

\author{
MARLON M.V. LEITE ${ }^{1}$ | ANA M. F. BARELAํ' | JOSÉ A. BARELA² \\ 1 Institute of Physical Activity and Sport Sciences, Cruzeiro do Sul University, São Paulo, SP, Brazil. \\ 2 Institute of Biosciences, São Paulo State University (UNESP), Rio Claro, SP, Brazil.
}

Correspondence to: José A. Barela. Av. 24-A, 1515, Bela Vista, Rio Claro, SP, 13506-900

email: jose.barela@unesp.br

https://doi.org/10.20338/bjmb.v15i1.238

\begin{abstract}
HIGHLIGHTS
- Time spent using electronic devices was increased during the pandemic period.

- Children from Poá city maintain their play time while social distancing.

- Pandemic restrictions did not impact total sleeping time in children from Poá city.

\section{ABBREVIATIONS \\ ANOVA Analyses of variance \\ COVID-19 Coronavirus disease \\ SARS-Cov-2 Severe acute respiratory syndrome \\ SPSS Statistical Package for Social \\ Sciences software}

MANOVA Multivariate analyses of variance
\end{abstract}

PUBLICATION DATA

Received 19012021

Accepted 25022021

Published 01032021
BACKGROUND: The disease caused by the novel coronavirus (COVID-19) has produced one of the most dramatic health crises, impacting humans' daily lives worldwide. Social distancing and lockdown measures have limited everyone's daily activities and have likely also affected children's physical activity.

AIM: To investigate physical activity and electronics use during COVID-19 social distancing in children from the city of Poá, São Paulo.

METHOD: Data from 28 children (10 males, 18 females) were obtained on two occasions: pre-pandemic (October 2019) and during the pandemic (May 2020). To further examine possible changes in physical activity, data from another sample of 40 children (20 males, 20 females) were obtained during the pandemic (May 2020).

From both cohorts, anthropometric information and play, television, electronics, and sleep time expenditures were obtained using a questionnaire.

RESULTS: Results from the first cohort (28 children) showed similar time spent engaged in playful activities and sleeping before and during the pandemic. Although hours spent watching television remained constant, a dramatic increase in the overall electronics time expenditure was observed (from 3.4 to 5.8 hours/day) during the pandemic period. A comparison of the results for the two cohorts confirmed these findings: there were no between-group differences in the data obtained during the pandemic period.

CONCLUSION: Although the children maintained their play time while social distancing, an increase in the time spent using electronic devices was observed, possibly due to the characteristics of the social distancing implemented in Brazil, as well as the characteristics of the children's neighborhood.

\section{INTRODUCTION}

Severe acute respiratory syndrome coronavirus 2 (SARS-Cov-2), which causes an infection termed as coronavirus disease (COVID-19), might lead to acute respiratory distress syndrome and several other health issues, and in extreme cases, can lead to death. ${ }^{1}$ Presently, there are over 120 million global cases, and there have been more than 2.6 million deaths. ${ }^{2}$

Due to the lack of pharmacological resources to combat COVID-19, several protective behaviors have been recommended and adopted worldwide, such as avoiding physical contact, including handshakes, hugs, and kisses, and banning large social gatherings and events. More dramatic measures like self-isolation, social/physical distancing, home confinement, and quarantine have also been implemented and enforced. Such dramatic and unprecedented measures, at least in contemporary society, have altered the daily living activities of most of the world's population. ${ }^{3}$ Moreover, following the necessary COVID-19 procedures may lead reduced physical activity and increased sedentary behavior ${ }^{4}$ since measures such as isolation, social distancing, confinement, and 
quarantine restrict most people's freedom to engage in physical activities.

Lack of physical activity is just one of several health risks associated with lockdown and/or social distancing measures. Staying at home in observance of the COVID-19 pandemic measures has led people to increase the time they spend seated in front of screens, as lockdown has prompted a massive surge in teleworking, ${ }^{5}$ which, in turn, has increased sedentary behavior. In addition, although most people are expected to suffer some type of mental disorder amidst the pandemic, the lack of physical activity and the increase in sedentary behavior may lead to a significant portion of the population experiencing minor emotional adjustments. ${ }^{6}$ For instance, sleep time has increased in both adults ${ }^{4}$ and children, ${ }^{7,8}$ and children's sleep quality has worsened. ${ }^{7}$ Therefore, social distancing measures might not only impact physical activity, but also a person's behavior and health as a whole.

Despite all the changes that have been imposed due to the quarantine, little is known about the impact of social distancing measures on children's behavior. Children's daily activities have been severely impacted due to school closure. Instead of going to school and interacting with their peers, children must stay at home due to the lockdown, likely with little opportunity to engage in outdoor activities and interactions. A recent study showed a significant reduction in physical activity and an increase in sedentary behavior in Spanish children during a lockdown period. ${ }^{9}$ Similar results were observed even for very young children (3-year-olds) in Chile, who exhibited dramatic behavioral changes. ${ }^{7}$

Reduced physical activity in children and adolescents has several consequences. First, physical activity in the early years of life is critical to promote active habits in subsequent years, ${ }^{10}$ which is associated with health benefits. Moreover, the activities that are typically promoted in the school environment are critical to increase children and adolescents' participation in active play. ${ }^{11}$ Thus, social distancing and, more drastically, months-long lockdowns might not only affect physical participation at present, but also in the future. Therefore, it is necessary to further examine the effects of social distancing measures on children's physical activity. Thus, this study aimed to investigate physical activity and electronics use during COVID-19 social distancing among children from the city of Poá, São Paulo, Brazil.

\section{METHODS}

\section{Participants}

Two cohorts of children participated in this study. First, 28 children (16 girls, 12 boys) were evaluated on two occasions: before and during the implementation of COVID19 social distancing measures. On the first occasion, children were evaluated in October of 2019 (before the social distancing measures), and on the second occasion, the same children were evaluated in May of 2020 (after about two months of the implementation of social distancing measures).

Given the relatively small sample size, the second cohort, consisting of 40 children (24 girls and 16 boys), was also evaluated in May of 2020 (after about two months of social distancing measures). Data from this cohort were compared to the data obtained during social distancing (i.e., from the 28 children in the first cohort). Age and anthropometric information for both groups, taken at each evaluation time point, is depicted in Table 1.

The study participants were enrolled in the Poá, São Paulo public school system 
and come from a low middle class social background. Initial contact with the children's parents (October 2019) occurred at the children's schools. Parents were informed about the study's purpose and procedures, and they signed a consent form. Contact while social distancing measures were in place occurred via phone calls/text messages. Again, parents were informed about the procedures, and they signed a consent form. Therefore, all procedures were performed with the adequate understanding and written consent of the persons legally responsible for the participating children. Furthermore, the study was conducted with the approval of the Institutional Review Board.

Table 1 - Means (standard deviations) of chronological age, body mass, height and body mass index of each group at the moment of evaluation.

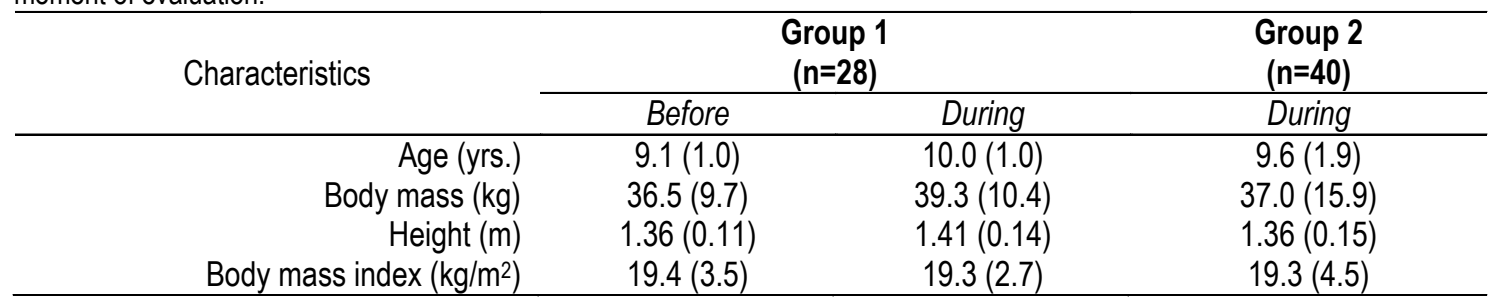

\section{Procedures}

Before the implementation of social distancing, the study participants' parents were contacted at their children's school. They completed the questionnaire (see below) in a designated room. The children's anthropometric information (body mass and height) was obtained at this time. While social distancing measures were in place, the same questionnaire was digitally sent to and returned by the parents, using media that was available to them. Parents were also asked to report their child's body mass and height (as measured independently).

This study utilized the SAÚDES-Vitória questionnaire, which is composed of 17 questions; five address the commute between home and school, three address leisure physical activities, and six address sedentary activities. Prior to its use in this study, the questionnaire was tested, ${ }^{12}$ validated,,$^{13}$ and employed in a study involving children of the same age as the present study's participants. ${ }^{14}$

At any time, parents could either physically or virtually contact the researchers to clarify questionnaire items. Due to its simplicity, the SAÚDES-Vitória questionnaire only takes a few minutes to complete, and parents reported no difficulty.

\section{Data Reduction}

Based on the responses to the SAÚDE-Vitória questionnaire, the total time that each child spent engaged in physical activity per week was obtained. Regarding sedentary activity, the number of hours per day that each child spent watching television was also obtained, along with the number of hours spent with electronic use. Finally, each child's sleeping time (hours/night) was also computed.

Each child's body mass index was calculated based on the anthropometric information, i.e., body mass and height, obtained via direct measurement or as reported by the participants' parents.

\section{Statistical analysis}


After accepting the normality and homogeneity of variance assumptions, two sets of tests were performed. The first set of analyses involved two multivariate analyses of variance (MANOVA) and two analyses of variance (ANOVA), with evaluation (before and during social distancing) as a factor, treated as a repeated measure. The first MANOVA had body mass, height, and body mass index as dependent variables, and the second had hours spent watching television and hours spent playing electronic games. The dependent variable in the first ANOVA was total time spent engaged in physical activity. In the second ANOVA, hours spent sleeping was the dependent variable.

The second set of analyses involved MANOVAs and three analyses of variance ANOVAs, with group as a factor (Group 1: $n=28$; Group 2: $n=40$ ). As dependent variables, the first MANOVA had body mass, height, and body mass index, and the second had hours spent watching television and playing electronic games. The first ANOVA had chronological age as the dependent variable, while the second and third had total time spent engaged in physical activity and hours spent sleeping, respectively.

When necessary, follow-up univariate analyses were performed. All the procedures were performed using the Statistical Package for Social Sciences software (SPSS), and an alpha level of 0.05 was adopted.

\section{RESULTS}

Table 2 depicts the hours the children in each group spent engaged in the various activities at each evaluation point.

Table 2 - Means (standard deviations) of hours in specific activities presented by both groups of children at the occasion of evaluation.

\begin{tabular}{rccc}
\multicolumn{1}{l}{ Activity } & \multicolumn{2}{c}{$\begin{array}{c}\text { Group 1 } \\
(\mathbf{n = 2 8})\end{array}$} & $\begin{array}{c}\text { Group 2 } \\
(\mathbf{n = 4 0})\end{array}$ \\
\cline { 2 - 4 } & Before & During & During \\
\hline Physical activity (hours/week) & $123.3(88.8)$ & $132.3(83.5)$ & $121.7(96.3)$ \\
Electronic games (hours/day) & $3.44(2.16)$ & $5.87(1.82)$ & $5.36(2.65)$ \\
Television (hours/day) & $2.80(1.37)$ & $2.92(1.19)$ & $3.07(1.30)$ \\
Sleep (hours/night) & $8.75(1.04)$ & $9.07(1.11)$ & $8.97(1.40)$ \\
\hline
\end{tabular}

\section{Comparison between before and during social distancing}

MANOVA revealed an evaluation effect (Wilks' Lambda $=0.661, \mathrm{~F}_{(3,25)}=4.27, p<$ $0.05)$ for the anthropometric variables. Univariate analyses showed that the children's body mass $\left(F_{(1,27)}=8.11, p<0.01\right)$ and height $\left(F_{(1,27)}=11.81, p<0.005\right)$ increased, but there was no change in body mass index $\left(F_{(1,27)}=0.02, p>0.05\right)$, as shown in Table 2 .

ANOVA did not reveal an evaluation effect for physical activity $(F(1,27)=0.16, p>$ 0.05). Similarly, ANOVA did not reveal an evaluation effect for time spent sleeping $\left(F_{(1,27)}=\right.$ $1.55, p>0.05$ ). However, MANOVA revealed an evaluation effect (Wilks' Lambda $=0.062$, $\left.F_{(2,26)}=198.08, p<0.001\right)$ for sedentary activity. Univariate analysis showed that while there was no difference between evaluations for television $\left(F_{(1,27)}=0.29, p>0.05\right)$, time spent playing electronic games increased during social distancing $\left(F_{(1,27)}=36.83, p<\right.$ 0.001) (Table 2). 


\section{Comparison between cohorts during social distancing}

ANOVA did not reveal a difference in age $\left(F_{(1,66)}=1.05, p>0.05\right)$ between cohorts, nor did MANOVA reveal anthropometric differences between cohorts (Wilks' Lambda = $0.947, F_{(3,64)}=1.20, p>0.05$ ) (Table 1). ANOVA also did not reveal any effect for physical activity $\left(F_{(1,66)}=0.22, p>0.05\right)$ and time spent sleeping $\left(F_{(1,66)}=0.09, p>0.05\right)$ in either cohort. Finally, MANOVA did not reveal any sedentary activity effect in either cohort (Wilks' Lambda $\left.=0.982, F_{(2,65)}=0.58, p>0.05\right)$ (Table 2).

\section{DISCUSSION}

The purpose of this study was to investigate physical activity and use of electronics during COVID-19 social distancing among children from the city of Poá, São Paulo, Brazil. Our results showed that, in a small cohort of children, time spent engaged in active play and time spent sleeping were similar before and at the time of the implementation of social distancing measures. However, results showed an increase in hours spent using electronic devices. These findings were confirmed in a comparison with the results from the larger cohort of children.

It is surprising that there was no difference in the time children spent playing before and during the implementation of COVID-19 social distancing measures. In other countries, social distancing and lockdown measures have restricted people's mobility, leading to decreased physical activity and increased sedentariness among adults ${ }^{4}$ and young children, ${ }^{7,9}$ but it seems that this is not the case for the Brazilian children who participated in this study. Several issues could be related to our children's behavior. First, Brazilian social distancing measures did not prohibit people from going out and thus never effectively restricted people's mobility. Although children might differ from adults in terms of going out behavior, it was still possible for children to move around the area around their home, playing by themselves and/or with their friends in the neighborhood. Second, although the city of Poá is in the São Paulo metropolitan area, it is mostly populated by houses and townhouses, allowing children to use front- and backyard spaces to move around in and play. In fact, young children in rural Chile who had space to play at home were less affected by the restrictions than children living in urban areas, who had less space to play, such as those living in apartments. ${ }^{7}$

Despite the fact that there was no difference in the time spent playing before and during the implementation of the social distancing measures, children might still be less active during social distancing. A relatively recent study ${ }^{11}$ observed that children from the same city and region spent about three times more time engaged in physical activity when activities such as commuting to school and other places, and sport practice were considered. As our results have shown, time spent playing did not differ before and during the implementation of the social distancing measures, but children from the present study might not be performing and/or enrolled in the same amount of physical activity as children in their age group typically did prior to the pandemic. This suggestion needs to be considered with caution and explored further with additional research.

Another important finding from this study is the dramatic increase in the use of electronic devices. As has already been observed in adults, people in general are spending more time sitting in front of screens, ${ }^{5}$ and this seems to be the same with the children in this study. Our results showed an increase in the amount of time that children 
spent playing electronic games, although there was no increase in time spent watching television. Aguilar-Farias and colleagues ${ }^{7}$ also observed an increase in time spent in front of a screen in young children, but they did not specify the activities involved. Thus, it seems that at the beginning of the adoption of social distancing measures (May 2020), a fair amount of the time that children would have otherwise spent at school was used to play games on electronic devices. As observed in adults, who spent more time sitting in front of computers due to the massive surge in teleworking, ${ }^{5}$ our children also increased the amount of time they spent sitting in front of screens, albeit to play games. It is important to note that at the time of data collection, many remote classroom activities had still not been fully implemented; hence, the amount of time children spend using electronic devices might have increased even more subsequently.

Increased use of electronic devices is also an indicator that children's sedentariness might have increased due to the pandemic-induced mobility restrictions. Surprisingly, no difference in the time spent sleeping was observed for children, unlike adults, for whom longer sleeping periods have been noted. ${ }^{4}$ Aguilar-Farias and colleagues ${ }^{7}$ observed that although young children spent more time sleeping, their sleep quality decreased. Unfortunately, this study did not examine quality of sleep in older children, which would have provided a means of comparison with these previous data.

This study has several limitations. First, the sample size involved in direct comparison, i.e., before and during the implementation of COVID-19 restrictions, was small $(n=28)$. This was due to the difficulties we experienced contacting and obtaining cooperation from the children's family members. However, the second, larger cohort of children $(n=40)$ provided similar information, corroborating the results obtained in the smaller cohort. Second, no direct measure was found regarding physical activity. Again, the social distancing measures prevented any action regarding the direct measure. Finally, our results are based on data that were obtained almost one year ago and might not reveal the actual picture at present. New actions are underway in order to obtain new data, but execution is challenging due to the dramatic changes that Brazilian society has experienced, given the high number of COVID-19 infections and the concomitant adoption of new distancing measures.

\section{CONCLUSION}

Brazilian children from Poá remained constant in terms of the total time they spent engaged in playful activities in the initial stage of the implementation of COVID-19 social distancing measures; however, indirect measures indicated a reduction in their overall level of physical activity. An increase in the time spent using electronic devices was observed, even though remote schooling had not yet been or was just beginning to be implemented at the time. The pandemic restrictions did not impact total time spent sleeping. 


\section{REFERENCES}

1. Garnier-Crussard A, Forestier E, Gilbert T, Krolak-Salmon P. Novel coronavirus (COVID19) epidemic: what are the risks for older patients? J Am Geriatr Soc. 2020;68:939-940. 10.1111/jgs.16407.

2. Who. Coronavirus (COVID-19) dashboard, https://covid19.who.int (2021, accessed March 18t, 2021 2021).

3. Hall G, Laddu DR, Phillips SA, Lavie CJ, Arena R. A tale of two pandemics: How will COVID-19 and global trends in physical inactivity and sedentary behavior affect one another? Prog Cardiovasc Dis. 2021;64:108-110. 10.1016/j.pcad.2020.04.005.

4. Janssen X, Fleming L, Kirk A, Rollins L, Young D, Grealy M, et al. Changes in physical activity, sitting and sleep across the COVID-19 national lockdown period in Scotland. Int J Environ Res Public Health. 2020;17. 10.3390/ijerph17249362.

5. Belzunegui-Eraso A, Erro-Garcés A. Teleworking in the conxtext of the COVID-19 crisis. Suatainability. 2020;12:3362.

6. Li S, Wang Y, Xue J, Zhao N, Zhu T. The impact of COVID-19 epidemic declaration on psychological consequences: a study on active weibo users. Int J Environ Res Public Health. 2020;17. 10.3390/ijerph17062032.

7. Aguilar-Farias N, Toledo-Vargas M, Miranda-Marquez S, Cortinez-O'ryan A, Cristi-Montero $\mathrm{C}$, Rodriguez-Rodriguez $\mathrm{F}$, et al. Sociodemographic predictors of changes in physical activity, screen time, and sleep among toddlers and preschoolers in Chile during the COVID-19 pandemic. Int J Environ Res Public Health. 2020;18. 10.3390/ijerph18010176.

8. Dellagiulia A, Lionetti F, Fasolo M, Verderame C, Sperati A, Alessandri G. Early impact of COVID-19 lockdown on children's sleep: a 4-week longitudinal study. J Clin Sleep Med. 2020;16:1639-1640. 10.5664/jcsm.8648.

9. Alonso-Martinez AM, Ramirez-Velez R, Garcia-Alonso Y, Izquierdo M, Garcia-Hermoso A. Physical activity, sedentary behavior, sleep and self-regulation in Spanish preschoolers during the COVID-19 lockdown. Int J Environ Res Public Health. 2021;18. 10.3390/ijerph18020693.

10. Goldfield GS, Harvey A, Grattan K, Adamo KB. Physical activity promotion in the preschool years: a critical period to intervene. Int J Environ Res Public Health. 2012;9:1326-1342. 10.3390/ijerph9041326.

11. Leite MMV, Barela JA. Extra opportunity increases physical activity levels of children. Russian Journal of Physical Education and Sport. 2017;12:41-48.

12. Checon K, Fonseca VM, Faria CP, Carletti L, Molina MCB. The reproducibility of the Saúdes: Vitória study's physical activity assessment questionnaire for children. Rev Bras Saude Mater Infant. 2011;11:173-180.

13. Fernandes CDR. Validação do questionário de atividade física em crianças de 9 e 10 anos de idade. Dissertation, Universidade Federal do Espírito Santo, Vitória, ES, Brasil, 2012. 
14. Andrade Neto F, Eto FN, Pereira TS, Carletti L, Molina Mdel C. Active and sedentary behaviours in children aged 7 to 10 years old: the urban and rural contexts, Brazil. BMC Public Health. 2014;14:1174. 10.1186/1471-2458-14-1174.

Citation: Leite MMV, Barela AMF, Barela JA. Playful activity remained constant while electronics use increased in children during social distancing amidst the COVID-19 outbreak: A Poá's pilot study. BJMB. 2021:15(1):26-33.

Editors: Dr Fabio Augusto Barbieri - São Paulo State University (UNESP), Bauru, SP, Brazil; Dr José Angelo Barela São Paulo State University (UNESP), Rio Claro, SP, Brazil; Dr Natalia Madalena Rinaldi - Federal University of Espírito Santo (UFES), Vitória, ES, Brazil.

Copyright:@ 2021 Leite, Barela and Barela and BJMB. This is an open-access article distributed under the terms of the Creative Commons Attribution-Non Commercial-No Derivatives 4.0 International License which permits unrestricted use, distribution, and reproduction in any medium, provided the original author and source are credited. Funding: This research did not receive any specific grant from funding agencies in the public, commercial, or not-forprofit sectors.

Competing interests: The authors have declared that no competing interests exist.

DOI: https://doi.org/10.20338/bjmb.v15i1.238 